\title{
The Pursuit of Brain-Language Relationships
}

\author{
Nina F. Dronkers \\ VA Northern California Health Care System and University of California, Davis
}

The past century has been a time of many new developments in the fields of language and neuroscience. We have seen the growth of linguistics and the application of its theories to the study of aphasia. We have learned much about neurophysiology and neural structures and the mechanisms of brain injury and recovery. At the same time, the prevailing model concerning the brain areas that subserve language has changed relatively little. In this regard, we have tended to rely on nineteenth-century theories of language localization and have been reluctant to take advantage of our new methods and technologies to explore additional brain regions, novel ideas, or alternative models. It would be my hope for the next century of the new millenium that we would take advantage of these new tools and use them to broaden our perspective regarding additional brain-language relationships and the integration of these different brain areas in the processing of language.

The traditional model still describes Broca's area, Wernicke's area, and the arcuate fasciculus as the key structures involved in language. We believe that Wernicke's area controls all language comprehension, Broca's area all language production, and that the transmission of information between these areas is facilitated by the arcuate fasciculus. We assume that all patients with Broca's aphasia have lesions in Broca's area, that all patients with Wernicke's aphasia have lesions in Wernicke's area, and that all patients with conduction aphasia have lesions in the arcuate fasciculus. We pass this information on to our patients, our students, and our colleagues, and we rarely question whether it is, in fact, true.

Recent studies have found that the traditional model of brain-language relationships is not always supported (e.g., Basso, Lecours, Moraschini, \& Vanier, 1985; Mohr, 1976; Murdoch, 1988; Vignolo, Boccardi, \& Caverni,

Address correspondence and reprint requests to Nina F. Dronkers, Ph.D., VA Northern California Health Care System and University of California at Davis, 150 Muir Road (126s), Martinez, CA 94553. E-mail: dronkers@ucdavis.edu; dronkers@ebire.org.

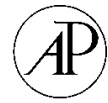


1986). In our own work in correlating the speech and language deficits of our aphasic patients with the sites of their lesions, we have also found that the traditional model does not adequately explain the data (for a review, see Dronkers, Redfern, \& Knight, 1999). For example, we find that many patients with Broca's and Wernicke's aphasia do not have the expected lesion and many patients have lesions in these classic areas without the predicted Broca's or Wernicke's aphasia. After several years of collecting data on chronic aphasic patients, we find that only $85 \%$ of patients with chronic Broca's aphasia have lesions in Broca's area, and only $50-60 \%$ of patients with lesions in Broca's area have a persisting Broca's aphasia. We also find that only $65 \%$ of patients with chronic Wernicke's aphasia have lesions in Wernicke's area, and approximately $30 \%$ of fluent aphasic patients with lesions in Wernicke's area have a persisting Wernicke's aphasia. Patients with conduction aphasia tend not to have lesions in the arcuate fasciculus at all, but rather in the superior temporal gyrus and inferior parietal lobule. Those patients with lesions in the arcuate fasciculus have a more complete disruption in the transmission of language information to frontal lobe speech mechanisms, such that the only speech produced is single repetitive words or syllables, a far more severe deficit than the repetition deficit predicted by traditional theory.

Why is there such a discrepancy between the old data and the new? First of all, we forget that Broca and Wernicke had very little data to work with. Broca based most of his conclusions on two autopsied cases, the brains of whom were never cut. His first case had multiple strokes and a history of seizures (Broca, 1861b) while the second had been admitted several years earlier for dementia (Broca, 1861a). Broca's subsequent cases were presented to him, but records were not kept on these and it is not clear whether the language deficit was exactly the same or that the lesion was restricted to just Broca's area. Wernicke also had only two cases, one of which recovered after seven weeks and was never autopsied while the second was demented with extensive neuropathological findings in addition to a lesion somewhere in the posterior superior temporal gyrus (Wernicke, 1874).

Despite their important contribution to the field at the time, these are not the rigorous data we require today for mapping brain-behavior relationships. The localization data we draw on now are carefully controlled and include only patients without previous neurologic or psychiatric complications and whose handedness and language histories are also considered. These patients participate in extensive language and behavioral testing to determine their deficits and concurrently undergo structural neuroimaging (usually 3D MRI) to determine the precise extent of the lesion (e.g., Dronkers, 1996). These methods and tools are substantially different from those that were available to Broca and Wernicke and allow us to evaluate brain-behavior relationships more closely than those eminent scientists could ever dream of doing.

As a result, we can now see beyond those traditional relationships and 
begin to use our new methods to refine these relationships, discover new ones, and consider how they might interact to produce language. Functional neuroimaging can add to the lesion work by clarifying what these traditional areas might do and defining new areas that also contribute to language processing. Yet, most functional imaging studies have resorted to selecting only traditional areas as regions of interest and have resisted the opportunity to let the data drive the discovery or the confirmation of new functional areas (with notable exceptions, e.g., Mazoyer, Tzourio, Frak, Syrota, Murayama, Levrier, et al., 1993; Peterson, Fox, Posner, Mintun, \& Raichle, 1988). My hope for the new century is that we can release ourselves from thinking that Broca's and Wernicke's areas are the only important language areas, that instead, they might be part of a more rich and complex system, and that we will use our new-found technologies and our knowledge about language to suggest new theories and models that can better explain how the brain processes language.

\section{REFERENCES}

Basso, A., Lecours, A. R., Moraschini, S., \& Vanier, M. 1985. Anatomoclinical correlations of the aphasias as defined through computerized tomography: Exceptions. Brain and Language, 26, 201-229.

Broca, P. 1861a. Nouvelle observation d'aphemie produite par une lesion de la troisieme circonvolution frontale. Bulletins de la Societe d'anatomie (Paris), 2e serie, 6, 398-407.

Broca, P. 1861b. Remarques sur le siege de la faculte du langage articule, suivies d'une observation d'aphemie (perte de la parole). Bulletins de la Societe anatomique (Paris), $2 \mathbf{e}$ serie, 6, 330-357.

Dronkers, N. F. 1996. A new brain region for coordinating speech articulation. Nature, 384, $159-161$.

Dronkers, N. F., Redfern, B. B., \& Knight, R. T. 1999. The neural architecture of language. In M. S. Gazzaniga (Ed.), The cognitive neurosciences. Cambridge, MA: MIT Press.

Mazoyer, B. M., Tzourio, N., Frak, V., Syrota, A., Murayama, N., Levrier, O., Salamon, G., Dehaene, S., Cohen, L., \& Mehler, J. 1993. The cortical representation of speech. Journal of Cognitive Neuroscience, 5(4), 467-479.

Mohr, J. P. 1976. Broca's area and Broca's aphasia. In H. Whitaker \& H. Whitaker (Eds.), Studies in neurolinguistics (Vol. 1, pp. 201-233). New York: Academic Press.

Murdoch, B. E. 1988. Computerized tomographic scanning: Its contributions to the understanding of the neuroanatomical basis of aphasia. Aphasiology, 2(5), 437-462.

Peterson, S. E., Fox, P. T., Posner, M. I., Mintun, M., \& Raichle, M. E. 1988. Positron emission tomographic studies of the cortical anatomy of single-word processing. Nature, 331, 585589.

Vignolo, L. A., Boccardi, E., \& Caverni, L. 1986. Unexpected CT-scan findings in global aphasia. Cortex, 22, 55-69.

Wernicke, C. 1874. Der aphasische symptomencomplex. Breslau: Kohn and Weigert. 